\title{
Mudanças nas formas de produção na indústria e a saúde dos trabalhadores
}

\author{
Changes in the forms of industrial production \\ and their effects on workers' health
}

\author{
Rita de Cássia Pereira Fernandes ${ }^{1}$ \\ Ada Ávila Assunção ${ }^{2}$ \\ Fernando M artins Carval ho ${ }^{1}$
}

${ }^{1}$ Departamento deM edicina Preventiva e Social, FaculdadedeM edicina, UniversidadeFederal da Bahia. Av. Reitor Miguel Calmon $s / n$, Canela. 40420-060 Salvador BA. ritapfernandes@uol.com.br ${ }^{2}$ Departamento de M edicina Preventiva e Social, UniversidadeFederal de M inas Gerais.
Abstract This study aimed to identify determinants of health in workers of plastic industries. Production organization, machinery from maintenance and productive areas, and workers' characteristics of 14 plastic industries from Greater Salvador, Bahia State, Brazil, weredescribed. Data were collected about development policy of each company; marketing, operational procedures; production and quality requirements, and formal rules of work organization. High strain management techniques for production time reduction havebeen implemented. Theincrease of work rhythm, reduction of break time, and a situation of high cognitivedemand imposeto workersanomalous body positioning for performing tasks that imply repetitive movements. Physical and psychosocial demands (repetitive work, lower control of the worker on his own tasks, time pressure and job dissatisfaction) composea complex of conditions adverse to workers' health. Changes in production management, personnel and business impose new strains into the development of task by the workers and bringing in new risk factors to workers' health.

Key words Repetitivestrain injury, Occupational diseases, Repetitive task, Plastic industry, O ccupational stress
Resumo Buscou-se identificar possíveis determinantes de efeitos na saúde dos trabalhadores em indústrias plásticas. Descreve-se a organização da produção, trabalhadores e maquinário das áreas de produção e manutenção de catorze indústrias plásticas da Região M etropolitana deSalvador. Coletaram-se dados sobre política de de senvolvimento de cada empresa, mercado, procedimentos operacionais, exigências de produção e de qualidade e as regras formais da organização do trabalho. I mplementam-se técnicas de gestão com forte exigência de redução do tempo da produção. 0 aumento do ritmo do trabalho, a redução de pausas e uma situação de alta demanda cognitiva impõem aos trabalhadores posturas anômalas para execução das tarefas com movimentos repetitivos. Demandas físicas e psicossociais ( trabalho repetitivo, baixo controle dos trabal hadores sobre suas tarefas, pressão de tempo e insatisfação no trabalho) compõem um universo de condições desfavoráveis para a saúde de trabaIhadores. M udanças na gestão da produção, de pessoal e dos negócios impõem novas exigências aos trabalhadores no desenvolvimento das tare fas, configurando novos fatores de risco para a saúde dos trabalhadores.

Palavras-chave Lesões por efforços repetitivos, Doenças relacionadas ao trabalho, Trabalho re petitivo, Indústria plástica, Estresse ocupacional 
Introdução

As formas de adoecimento de trabalhadores da indústria guardam relação com as diferentes modalidades de gestão do trabalho e da produção. As exigências sobre o corpo e sobre as capacidades cognitivas epsíquicas no ambiente detrabalho podem se expressar como doenças relacionadas ao trabalho, entre elas, os distúrbios musculoesqueléticos (DME) e o sofrimento psíquico, identificado como estresse ocupacional.

Mundialmente, existe preocupação crescente com as consequências econômicas e sociais dos distúrbios musculoesqueléticos (DME) ${ }^{1-5}$. No Brasil, os quadros clínicosincapacitantes de DM E em trabalhadores da indústria constituem parcela relevante da demanda aos Serviços de Saúde do Trabal hador do Sistema Ú nico de Saúde ${ }^{6}$. Em função da inexistência de um sistema de informação consolidado para morbidade ocupacional no país, não há dados sobre a ocorrência desses distúrbios, sem falar na inexistência de dados sobre a distribuição de doenças, por ramo econômico deatividade. 0 quehá disponível são dados da Previdência Social que, além de se restringirem à população com vínculo formal de emprego, beneficiária do auxílio-acidentário, não são estratificados por categorias profissionais ou ramos. É possível que um melhor tratamento analítico dos dados previdenciários permita em futuro próximo conhecer a distribuição de agravos por ramo.

O sofrimento psíquico, de menor visibilidade devido às suas próprias características, acaba sendo experimentado pelos trabalhadores e abordado como decorrentes de características psicológicas individuais, sem habitualmenteser relacionado com o trabalho7. Os DM E e o sofrimento psíquico, para falar ao menos de duas modalidades de adoecimento mais referidas no momento atual de mudanças no mundo do trabalho, podem determinar incapacidade para o trabal ho e importantes consequências na vida do trabalhador, além deocorrerem, muitas vezes, simultaneamente no mesmo trabalhador. A literatura epidemiológica sobre os fatores de risco para os DM E e para o estresse ocupacional é ampla. No entanto, as características da produção e das técnicas de gestão de pessoal, precursores fundamentais do risco, nem sempre são abordadas em estudos do campo da saúde do trabalhador.

D efiniu-se, então, pela realização de uma investigação em um ramo industrial, com o objetivo de descrever a organização e o funcionamento de indústrias do ramo plástico, identificando elementos da reestruturação da produção e suas consequências sobre a saúde de trabalhadores. Pressupostos epidemiológicos, tecnológicos e sociais, conforme preconiza a Vigilância em Saúde do Trabalhador ${ }^{8,9}$, indicavam a oportunidade de se realizar o estudo no ramo plástico. 0 componente social remete à situação econômica e, especialmente, à organização de trabalhadores e empregadores do ramo. 0 estudo em empresas de um mesmo ramo e não em empresas de diferentes ramos pode viabilizar que os resultados obtidos sejam incorporados na agenda das representações de trabalhadores e empregadores, com capacidadedereproduzir as recomendações para os seus representados. 0 componente tecnológico diz respeito ao tipo de tecnologia empregada nos processos produtivos e o componente epidemiológico refere-se às informações sobre os possíveis fatores de risco para o adoecimento de trabalhadores. 0 Sindicato dos TrabaIhadores do Ramo Químico inclui na categoria representada os trabalhadores das indústrias de plásticos. Este é o maior sindicato das regiões Norte e N ordeste do país, com relevante expressão nas lutas pela saúde dos trabalhadores e, portanto, com uma capacidade de reproduzir na ação junto aos ambientes de trabalho as recomendações oriundas de uma investigação como a presente. Os processos tecnológicos empregados na indústria de plásticos na Região M etropolitana de Salvador implicam, predominantemente, trabalho mecanizado e não automatizado. Esse tipo de trabalho envolve exigência de força com os membros superiores, repetitividade e ritmo acelerado, estando associado com maior ocorrência de doenças relacionadas ao trabalho, segundo vasta literatura epidemiológica. Esses foram os pressupostos que indicaram a escolha do ramo plástico.

\section{M aterial e métodos}

A cadeia produtiva de plásticos se inicia com a produção das matérias-primas (eteno, propeno, benzeno e paraxileno) pelas indústrias de primeira geração, a partir da nafta extraída do petróleo. N as indústrias de segunda geração, essas matérias-primas dão origem às mais diversas resinas: polietileno, policloreto de vinila, polipropileno e poliestireno, entre outras. Em terceiro lugar, vêm as chamadas indústrias de transformação, cuja gama de produtos inclui artigos domésticos, eletroeletrônicos, automotivos, têxteis, artigos para indústria de calçados, artigos 
da construção civil e variadas embalagens ${ }^{10}$. Todas as empresas incluídas neste estudo são de terceira geração - indústrias de transformação de material plástico.

Foram estudadas todas as empresas de pe queno e médio porte, com mais de 35 trabalhadores, localizadas na Região M etropolitana de Sal vador e registradas na Federação das Indústrias do Estado da Bahia. Após um período intenso denegociação para o acesso às empresas, iniciouse 0 estudo. 0 período de coleta de dados da investigação foi de 10 de abril a julho de 2002.

Para obtenção dos dados, foram realizadas visitas técnicas nas áreas de produção e manutenção das unidades fabris, observando-se o funcionamento e a organização da produção. Realizaram-se observações globais das tarefas desenvolvidas pelos trabal hadores dos setores de manutenção e produção. N esta etapa, visava-se conhecer a organização geral, o funcionamento da produção e os determinantes das tarefas. Registrou-se em diário de campo o resultado das observações e as informações coletadas junto aos gestores das empresas e aos trabalhadores, simultaneamente às observações. Uma vez estruturadas as informações sobre o funcionamento e capacidadefísica instalada de cada fábrica, eram destacados os fatos relevantes da organização e gestão do trabalho, incluindo metas de produção. Foram feitos registros fotográficos dos locais de trabalho, do maquinário e dos trabalhadores em atividade, para utilização no momento de descrição. Como etapa complementar, realizaram-se entrevistas semiestruturadas, utilizando-se roteiro padronizado ${ }^{11}$, coletando-se dados sobre história de cada empresa e sua política de desenvolvimento; seu mercado; sua geografia (localização, vias de acesso, qualidade do tecido industrial e social de suporte); a organização da produção; os procedimentos operacionais, em especial, as exigências de produção, de qualidade e de segurança e as regras formais da organização do trabalho. N essas entrevistas, considerando a natureza dos dados requeridos, os informantes foram indivíduos que exerciam funções de gestão dos negócios, como proprietários ou gerentes e representantes sindicais que detinham informações acerca das tendências dos negócios no ramo plástico.

Os indivíduos entrevistados foram esclarecidos sobre os objetivos da pesquisa e sobre a garantia de anonimato. 0 projeto da investigação foi aprovado pelo Comitê de Ética do Instituto de Saúde Coletiva da Universidade Federal da Bahia.

\section{Resultados ediscussão}

Das dezessete empresas identificadas, três se recusaram a participar do estudo. As dificuldades de acesso de pesquisadores aos ambientes internos das fábricas são amplamente reconhecidas na literatura clássica da epidemiologia ocupacional, o que tem resultado na realização de estudos epidemiológicos predominantementecom populações de trabalhadores afastados do trabalho. Portanto, o processo de obtenção do acesso em catorze das dezessete fábricas pode ser considerado muito positivo. Aliás, na fase de planejamento do estudo, não seidentificou na literatura indexada nenhuma investigação epidemiológica no Brasil realizada dentro dos ambientes fabris. As catorze unidades industriais distribuídas segundo processo tecnológico da produção e número detrabalhadores são apresentadas no Q uadro 1. A maior parte das empresas (dez das catorze) destina-seà fabricação deembalagens plásticas em sacaria, o que reflete um parque industrial ainda incipiente quanto à sofisticação tecnológica. 0 processo industrial de fabricação de embalagens em sacaria requer uma tecnologia de menor complexidade frente a outras modalidades no setor detransformação plástica, a exemplo dos processos à base de injeção de plástico e rotomoldagem. As empresas compunham uma população de 1.342 trabalhadores, dos quais 1.177 estavam inseridos em atividades de manutenção e operação.

Funcionamento e organização do processo produtivo e o mercado.

Sobre a gestão da produção

e a identificação de situações geradoras de fatores de risco físicos ou psicossociais para a saúde dos trabalhadores

As empresas do segmento de sacaria, cuja origem não ébaiana, contam com outras unidades fabris no país. A capacidade de produção dessas novas unidades na Bahia supera a das empresas previamente instaladas no estado. Este diferencial na capacidade de produção e, em decorrência, no poder de negociação de preços e prazos de matéria-prima e insumos, tem mudado o panorama de competitividade.

Para os empresários, a situação é de ameaça: A vinda do pessoal novo foi negativo para a indústria daqui. Eles estão pegando o incentivo, renovando o parque deles em São Paulo, que é forte, e irão embora. Estas informações revelam a competitividade instalada, mas são negadas por em- 
Quadro 1. Empresas do ramo plástico segundo número total de trabalhadores e de trabalhadoras, produtos e processo tecnológico. Região Metropolitana de Salvador, 2002.

\begin{tabular}{|c|c|c|c|c|}
\hline Empresa & $\begin{array}{l}\text { Número total de } \\
\text { trabalhadores }\end{array}$ & $\begin{array}{l}\text { Mulheres } \\
\text { № }(\%)\end{array}$ & Segmento do ramo/Produtos & $\begin{array}{l}\text { Processo } \\
\text { tecnológico }\end{array}$ \\
\hline 1 & 120 & $82(68,0)$ & Brinquedos/Bonecas & $\begin{array}{l}\text { Injeção de plástico } \\
\text { Rotomoldagem }\end{array}$ \\
\hline 2 & 49 & $13(26,5)$ & $\begin{array}{l}\text { Sacaria/Sacos plásticos, sacolas para } \\
\text { supermercado, bobinas técnicas }\end{array}$ & $\begin{array}{l}\text { Extrusão de filme } \\
\text { plástico }\end{array}$ \\
\hline 3 & 127 & $12(9,4)$ & Sacaria/Bobinas de ráfia & $\begin{array}{l}\text { Extrusão e } \\
\text { tecelagem de ráfia }\end{array}$ \\
\hline 4 & 102 & $05(4,9)$ & $\begin{array}{l}\text { Sacaria/Sacos valvulados para uso } \\
\text { industrial }\end{array}$ & $\begin{array}{l}\text { Extrusão de filme } \\
\text { plástico }\end{array}$ \\
\hline 5 & 114 & $14(12,3)$ & $\begin{array}{l}\text { Caixaria/Caixas para lixo, hortícolas, } \\
\text { açougue, engradados, EPI }\end{array}$ & Injeção de plástico \\
\hline 6 & 73 & $34(46,6)$ & $\begin{array}{l}\text { Sacaria/Sacos, sacolas, bobinas } \\
\text { técnicas }\end{array}$ & Extrusão \\
\hline 7 & 55 & $09(16,4)$ & $\begin{array}{l}\text { Sacaria/Bobinas de filme plástico } \\
\text { para sacaria industrial }\end{array}$ & Extrusão \\
\hline 8 & 44 & $11(25,0)$ & Sacaria/Sacos, sacolas & Extrusão \\
\hline 9 & 57 & $48(84,2)$ & $\begin{array}{l}\text { Sacaria/Sacos valvulados para uso } \\
\text { industrial }\end{array}$ & $\begin{array}{l}\text { Acabamento de } \\
\text { sacaria industrial }\end{array}$ \\
\hline 10 & 101 & $57(56,4)$ & Brinquedos & $\begin{array}{l}\text { Injeção } \\
\text { M oldagem à sopro }\end{array}$ \\
\hline 11 & 156 & $47(30,1)$ & $\begin{array}{l}\text { Sacaria/Sacolas plásticas para } \\
\text { supermercado }\end{array}$ & Extrusão \\
\hline 12 & 37 & $1(2,7)$ & $\begin{array}{l}\text { Sacaria/Sacos picotados para } \\
\text { hortícolas }\end{array}$ & Extrusão \\
\hline 13 & 150 & $60(40,0)$ & $\begin{array}{l}\text { Sacaria/Sacos picotados, sacolas, } \\
\text { sacaria industrial valvulada }\end{array}$ & Extrusão \\
\hline 14 & 157 & $5(3,2)$ & Tubos e conexões & Injeção \\
\hline
\end{tabular}

presários da indústria plástica, que estão fora do segmento de sacaria. Para estes, as empresas de sacaria que se instalaram vieram para ficar.

Existe uma grande diversidade nas instalações das fábricas de sacaria, desde as dimensões das áreas físicas destinadas aos setores produtivos até a tecnologia e o maquinário empregado. $\mathrm{N}$ ão se trata, portanto, de uma atividade com empresas homogêneas e com igual capacidade produtiva. 0 menor custo dos produtos plásticos das maiores empresas, em decorrência deum menor preço da matéria-prima ou da incorporação de um maquinário moderno, vem desestabilizando as empresas menores.

O segmento de transformação de material plástico (empresas de terceira geração) e, mais especificamente, o segmento de sacaria, fica entre dois blocos econômicos de capital intensivo, que 
são os fornecedores da matéria-prima (a resina plástica) e os compradores de sacaria.

Para alguns empresários, a ausência de uma política de preços de matéria-prima por parte do Pólo Petroquímico de Camaçari, com ajustes escalonados a depender do porte da empresa compradora, dificulta a concorrência entre as empresas de transformação de plásticos, as de terceira geração.

Um dos maiores clientes dos produtos plásticos, especialmentena área de sacaria, vem sendo as redes de supermercados. A política de preços adotada por estes grandes compradores é definida unilateralmente. Um outro cliente é 0 segmento de limpeza urbana, que não garante à economia local a reserva de mercado, podendo optar pela aquisição de sacaria em diferentes mercados e estados brasileiros.

$\mathrm{N}$ a perspectiva de reestruturação das empresas, há o exemplo, no segmento de sacaria, da empresa 9, instalada com o fim de assumir o setor de acabamento (corte e solda e valvulado) da sacaria industrial valvulada em filme plástico de um grupo empresarial que incorpora também as empresas 3 e 7. Antes da reestruturação do grupo, havia uma única empresa que realizava todo o ciclo produtivo, da extrusão ao acabamento. Em 1997, foi fechada e, para reiniciar sua produção, foi fragmentada em três unidades. Alguns dos empregados foram absorvidos pela empresa 3 e pelas demais do grupo empresarial, mas a maior parte, formada por mulheres, foi demitida. A empresa 9 foi instalada, em um município diferente, em área urbana, com outra razão social. Segundo o diretor desta empresa, a escolha deumaárea urbana se deu pela redução de custos com a desobrigação pela alimentação e transporte dos trabalhadores. A reestruturação das empresas desse grupo empresarial revela uma estratégia que visou, em primeiro lugar, através da instalação de uma planta nova (a empresa 7), entrar na competição do mercado de bobinas de filme plástico e, em segundo lugar, manter, através das empresas 3 e 9, a produção da sacaria tradicional.

Tendo em vista a possibilidade de ampliação da produção através de um novo maquinário, especialmente no setor de acabamento (particularmente no corte e solda), a alternativa encontrada pelas empresas de menor porte tem sido a incorporação de novas máquinas que passam a operar juntamente com as mais antigas. Esta situação pode ser ilustrada pela fabricação de embalagem para compras de supermercados (sacola plástica). As máquinas sacoleiras mais modernas efetuam corte e solda, realizando todas as etapas de fabricação dessa embalagem ao invés do processo em duas etapas realizado pelas máquinas tradicionais.

Para aumentar a produtividade, além da incorporação de novo maquinário, intensifica-se o ritmo de trabalho. 0 gerente de produção de uma empresa diz que"o ritmo aumentou em $60 \%$ com a chegada das máquinas novas; eu já dei 530 toneladas/mês com o maquinário atual, cuja capacidade prevista é de quatrocentas toneladas".

Técnicas e maquinário tradicionais e modernos passaram a conviver num mesmo ambiente. Esta situação, além de gerar para os trabalhadores a exposição às posturas anômalas e repetitividade, caracterizou-se pela implementação de técnicas de gestão voltadas para a intensificação do trabalho: operar mais de uma máquina e desenvolver destreza e habilidade sensório-motora, sob uma forte exigência de redução do tempo da produção. Em consequência, ocorre aumento do ritmo do trabalho, redução da possibilidade de fazer pausas, em uma situação de alta demanda que impõe posturas penosas para execução das tarefas.

\section{Estruturas hierárquicas}

As características identificadas nas indústrias do ramo estudado, em um contexto de reestruturação produtiva, evidenciam a manutenção de formas mais tradicionais de gestão do trabal ho e a incorporação de elementos das formas mais modernas nas empresas de maior capital. Algumas empresas neste ramo industrial têm estrutura familiar e apresentam, em geral, pequeno número de cargos, ocupados pelos próprios proprietários. Além de gerente industrial e alguns encarregados por setor, todos os demais são operadores, ajudantes ou auxiliares. Com pequenas variações, a estrutura é composta de gerência administrativa, gerência comercial ou devendas e gerência de produção ou industrial.

Quanto ao modelo de gestão de pessoal, vale ressaltar certos aspectos. Embora os sujeitos aqui estudados sejam formalmente vinculados às empresas, com relação de emprego padrão, as características do emprego permitem identificálo com o que vem sendo denominado de emprego precário, mais associado ao trabalho terceirizado do que ao trabal ho com vínculo direto com a empresa. Esses vínculos se caracterizam por limitados benefícios sociais, insegurança no trabalho, curto tempo de manutenção do emprego e baixos salários. N este ramo, observaram-se estratégias como o deslocamento de unidades 
fabris para o meio urbano, como forma de re dução de benefícios e atração de uma força de trabal ho considerada pelos empregadores como desqualificada emais vulnerável a sesubmeter às condições precárias oferecidas.

Em algumas empresas, os diretores exercem sua autoridade através de um poder centralizado, recorrendo com frequência a repreensões verbais em alto tom. Observou-se este comportamento mesmo em se tratando de diretor para encarregado, ou seja, nas relações com cargos mais destacados da hierarquia. Em uma empresa, observou-se que a presença do diretor na área de produção provocava mudança no ambiente, os trabal hadores faziam súbito silêncio e se voltavam para o objeto de trabalho em resposta a uma atitude de repreensão mesmo que não explícita. Um dos entrevistados, contratado como gerente de produção, depõe sobre esta situação: $\mathrm{N}$ as fábricas de plástico, ainda impera o chicote. Relata ocasiões em que interviu em episódios de agressão física envolvendo diretor de fábrica e trabalhadores: Em uma ocasião, eu e mais dois tivemos que segurar um rapaz que, revoltado com - que ouviu do dono da fábrica, buscou uma faca para atingi-lo e em outra vez eu assisti a um dono de fábrica tirar a camisa e chamar o peão para a briga na porta da fábrica. Evidenciaram-se relações, marcadas pelo autoritarismo, que são fontes de estresse, aumentando as demandas psicossociais e, em particular, a insatisfação dos trabalhadores. 0 estresse pode prejudicar a redução da ativação fisiológica do sistema muscular aos níveis de repouso, durante as pausas ou após o trabalho, mantendo a alta atividade muscular em algumas unidades motoras, contribuindo possivelmente para a ocorrência de efeitos sobre a saúde $e^{4,7,12,13}$.

\section{Jornadas de trabal ho e demandas extras}

Em geral, o trabal ho nos setores de produção é organizado em turnos, ao passo que a manutenção é organizada em regime administrativo.

$\mathrm{N}$ as empresas com produção sazonal, frequentemente os trabalhadores deturno são transferidos para o horário administrativo, no período de baixa produção, ou então se suspende 0 turno noturno, redistribuindo-se os trabalhadores nos demais turnos, a fim de reduzir o custo com horas de trabalho noturno.

Outra opção adotada é o sistema de banco de horas. Segundo o gerente industrial de uma empresa, estesistema compensa as jornadas mais longas no período de maior produção, com féri- as e folgas coletivas no período de menor atividade. No entanto, viu-se que, nesta empresa, no período de menor atividade, a jornada podia chegar a cinquenta horas por semana. Além disto, $85,4 \%$ dos trabalhadores, neste período, trabalhavam em horas extras. Este seria o período de baixa produção, quando se compensariam as longas jornadas do outro semestre. A contradição entre o informado pelo gerente e o constatado pode ser explicado pelo fato desta empresa ter adotado a diversificação da produção, assumindo um contrato para fabricação de um novo item no período que seria de baixa produção. Esta alternativa, no entanto, não se fez sem consequências para os trabalhadores. 0 contrato implicava ainda a fabricação, pela primeira vez, de um outro produto, fora da cadeia produtiva da empresa.

Esta situação, além de implicar a exposição a longas jornadas de trabalho, é marcada por um ritmo de trabalho acelerado, com exigência de novas habilidades para atender a meta de entrega do produto no prazo exigido pelo cliente, em uma atividadequese caracteriza do ponto devista das demandas físicas pela repetitividade de movimentos com braços emãos. Para Llory ${ }^{14}$, quando decisões são adotadas, como a introdução de procedimentos de trabalho ou a adoção de nova técnica de trabalho, sem que os detalhes ou as dificuldades das operações sejam conhecidos, ocorrem desestabilizações do trabal ho, impedindo a expressão das habilidades adquiridas na prática cotidiana, com maiores dificuldades para superar as perturbações do processo.

Formas de controle da produtividade e da qualidade

Os registros de produtividade, em geral, são feitos em planilhas diárias com a contabilidade de número de bobinas ou de fardos de embalagem ou, ainda, dos metros de embalagem ou número deunidades fabricadas. No entanto, este registro não se constitui em uma fonte de informação para a gestão do negócio, ou seja, não chega a representar uma ferramenta para o planejamento ou avaliação da produção.

Em uma das empresas, a gerente industrial respondeu à questão sobre controle da produção afirmando: como há uma grande diversidade de produtos, os tempos variam muito. A exigência de uma maior produção é decorrência das demandas do mercado. Havendo um grande número de pedidos, amplia-se a carga horária, instituindo expediente aos sábados, sem planeja- 
mento prévio. Nesta situação, cabe aos trabaIhadores ajustarem-se às exigências dos organizadores da produção, que muitas vezes não sabem exatamente definir sua meta e, em geral, não oferecem as condições para sua obtenção. Identificam-se demandas psicossociais, como o baixo controle dos trabalhadores e sua submissão às condições exigidas pela produção. Esta forma de organização do trabalho incorpora as características dos processos geradores de estresse e possibilidade de adoecimento, conforme explicita o modelo demanda controle ${ }^{15}$ e outros modelos de estresse?.

O controlededesempenho individual fica sob responsabilidade dos encarregados, sem critérios explícitos de avaliação. Segundo uma encarre gada de pessoal de uma das empresas: Não há um sistema formal de avaliação, mas até os diretores conhecem e sabem quem é o bom operador.

Algumas vezes, as planilhas são utilizadas para avaliar o desempenho de cada operador, trocando-o de posto ou de máquina, quando a produção está baixa. Ressalta uma encarregada: Para não cometer injustiças, observa-se a produtividade individual ao tempo em que se observa o registro do tempo de funcionamento da máquina, já que o tempo parado para manutenção tem que ser computado porque não depende do operador. Evidencia-se que apenas as paradas para manutenção são consideradas. As demais perturbações do processo que exigem a intervenção do trabaIhador, com uso do tempo, embora possam de terminar queda na produtividade, não são reconhecidas. Por isto, os trabalhadores devem regular essas perturbações asseguran do as metas previstas, sob constrangimento temporal, constituindo-se uma situação de hipersolicitação do sistema musculoesquel ético (movimentos repetitivos, posturas anômalas e uso de força) e de alta exigência cognitiva.

Em outra empresa, a produtividade é avaliada com base na cronometragem. A cada novo produto, registra-se o tempo médio das etapas da produção e a produtividade é, então, baseada neste tempo médio. Ao ser indagado sobre os efeitos adversos oriundos da padronização de tempos, considerando a variabilidade dos modos operatórios entre os indivíduos ea variabilidade do processo, o gerente afirma que, ao tomar o trabal hador com uma capacidade de produção média para padronizar os tempos e movimentos, admite estar planejando e administrando da forma mais correta.

A gestão temporal da produção, dessa forma, não incorpora a noção de variabilidade, ado- tando uma perspectiva normativa que concebe 0 trabalho como sistema técnico estável, ao invés de um sistema sociotécnico no qual a variabilidade é estrutural ${ }^{14,16}$. Para Abrahão $0^{16}$, se existisse o operário médio e o posto de trabalho estável, 0 trabalho prescrito não guardaria nenhuma distância do trabalho real e a tarefa seria desenvolvida tal equal a sua prescrição; no entanto, não é isso o que ocorre.

Quanto ao padrão de qualidade dos produtos, em nenhuma das fábricas observou-se um setor ou uma função formalizada para seu controle. Ao serem indagados a respeito, os entrevistados admitem queo controleéfeito pelo próprio trabalhador, especialmente no corte esolda. No entanto, não há explicitação desta tarefa, muito menos reconhecimento das habilidades, apesar das exigências cognitivas em ritmo temporal intenso. Ao contrário, afirma-se quea "mão de obra é desqualificada".

Características da força de trabalho e divisão sexual do trabalho

A segregação por gênero determina um diferencial na exposição às cargas físicas no trabal ho.

N os setores de extrusão e impressão, são inseridos os homens, enquanto no acabamento, em geral, estão as mulheres. A distribuição da população por empresa e a proporção de muIheres segundo a natureza do processo produtivo da empresa podem ser vistas no Quadro 1.

0 segmento de brinquedos é o que mais emprega a força de trabal ho feminina ( $68 \%$ e $56,4 \%$ em duas empresas), seguido das empresas do segmento de sacaria, que realizam acabamento. U ma empresa que realiza exclusivamente as etapas de corte esolda e val vulado tem uma presença feminina marcante (84\%). A segregação por gênero no trabalho sugere a possibilidade de morbidade também distinta.

Não é apenas a divisão sexual do trabalho que chama aten ção nas empresas do ramo quanto à caracterização da força de trabalho. A contratação dos trabal hadores em ocupações inferiores às exigências das funções realizadas foi outracaracterística marcante. Observou-seque, em geral, os trabalhadores que operam máquinas nas indústrias estudadas não têm a ocupação de operador formalmente estabelecida. O peradores são contratados, em geral, como auxiliares ou ajudantes, cuja faixa salarial éinferior àquela dos contratados como operadores.

O setor em que os títulos de ocupação para os quais os trabal hadores são contratados ficam 
mais distantes da função que, de fato, desempe nham é o acabamento, especialmente o corte e solda e o valvulado, no segmento de sacaria. Quase toda a força de trabalho que opera junto às máquinas é classificada como ajudante ou auxiliar de produção, tanto as operadoras de máquina de corte e solda, quanto às operadoras de máquina de valvulado. Uma encarregada de pessoal de uma empresa justificou a política adotada argumentando que os líderes da produção seriam responsáveis pelas máquinas. Portanto, seriam eles os operadores, tendo em vista que, segundo as atribuiç̧ões formalizadas, durante as variabilidades e incidentes, eles seriam chamados para resolver e "mexer" nas máquinas, porque "as mulheres não sabem fazêlo", resume a entrevistada. N esta perspectiva, os demais, que, em geral, são mulheres, seriam apenas auxiliares. No entanto, foi possível constatar no estudo que as mulheres contratadas como auxiliares realizam ajustes e regulações frequentes nas máquinas, evitando a interrupção da produção. Em situação de trabal ho real, apenas as paradas para manutenção ou trocas de bobinas eram destinadas aos líderes ou encarregados.

Embora os sujeitos aqui estudados sejam formalmente vinculados à empresa, com relação de emprego padrão, as características do emprego permitem identificá-lo com o quevem sendo denominado de emprego precário: limitados bene fícios sociais, insegurança no trabalho, curto tempo de manutenção do emprego e baixos salári$05^{17,18}$. Vinculada a essa discussão sobre a precarização do trabalho, muitos têm se debruçado sobre as diferenças de gênero que caracterizam esse contexto. Discutem-se as atuais tendências de incorporação da força de trabalho feminina no mercado de trabalho à custa, muitas vezes, da submissão de mulheres a situações desvantajosas quanto à carreira, ao tipo de inserção e nível salarial. Além disso, o lugar destinado às mulheres tem sido marcado pela presença de fatores de risco para a saúde, como são os trabal hos que se caracterizam pela repetitividade das tar efas. Discute-se, assim, a maior vulnerabilidade das muIheres nesse processo ${ }^{19,20}$.

$\mathrm{Na}$ empresa 9, cujo processo de instalação foi descrito, há um encarregado de corte e solda e um trabalhador do sexo masculino registrado como operador de corte e solda. Todos os demais (54 dos 56 trabalhadores) são registrados como "auxiliar de produção" (seis homens e 48 mulheres). Entre esses, apenas aqueles mais recentemente contratados desenvolvem, de fato, atividade de "auxiliar" ("os que não vão para a máquina"); os demais são, efetivamente, operadores de máquina. Uma encarregada justifica a lógica que orienta as contratações: $N$ ão há promoção no setor de acabamento [corte e solda e valvulado], por isto não há plano de cargos e salários e nem precisa, porque o trabalho é muito mecânico, muito repetitivo, não há progressão.

Algumas características dos processos e técnicas de produção nas empresas

Setor de carga e descarga de matéria-prima e produto final

Em geral, utiliza-se o trabalho manual no deslocamento de cargas. Algumas vezes, não há área física destinada ao estoque. Assim, os trabalhadores devem improvisar, no espaço exíguo entre as máquinas, um local para a estocagem de matéria-prima e outros insumos.

Em uma empresa, segundo o encarregado, as carretas se aproximam para o desembarque da carga que é transportada, através de empilhadeiras, e armazenada. No entanto, durante as observações, constatou-se o descarregamento manual de matéria-prima da carreta realizado pelos próprios operadores de máquina. 0 transporte de toda a carga era feito para a área de estocagem, bem como sua arrumação e disposição. Constatou-se também que esta situação, diferente do informado previamente pelo encarregado, deviase a defeitos na empilhadeira, frequentes e recorrentes. A distância identificada entre o prescrito e o real evidencia as variabilidades do sistema sociotécnico e as demandas aos trabalhadores não previstas na descrição formal das tarefas ${ }^{21}$.

No setor de carga e descarga, as tarefas que exigem trabalho manual podem determinar hipersolicitação musculoesquelética, especialmente em região lombar, pescoço, ombros ou parte alta do dorso.

Setor de extrusão

A extrusão é o processo pelo qual a resina plástica é submetida ao calor para produção do filme plástico. N as empresas de sacaria, da extrusão saem as bobinas plásticas, de filme ou de fio, que são deslocadas para o setor de impressão. A pesar do uso de talhas, cepos e cavaletes, 0 esforço físico é evidente no manuseio de carga, ao empurrar as bobinas para conectá-las às máquinas e retirá-las dos equipamentos, implicando atividades com uso de força com os braços, inclinação e rotação de tronco (Figura 1).

Nos segmentos de caixaria, de brinquedos e detubos econexões, o processo de extrusão plás- 
tica ocorre acoplado à moldagem plástica dos produtos, através da tecnologia de injeção, de sopro ou rotomoldagem (Quadro 1). Nesses processos, chama atenção o caráter cíclico do trabalho e a exigência de movimentos repetitivos das extremidades superiores. A duração do ciclo éprogramada pelo encarregado no início do turno de trabalho, observando os parâmetros do processo de injeção (ou do processo de sopro) tempo necessário para a máquina fabricar a peça. Observou-se em uma empresa que o encarregado começa a regular a duração do ciclo pelo tempo mínimo. Definequarenta segundos eobserva a peça ejetada. Caso a peça saia fora dos padrões de qualidade, aumenta-se o tempo. Se em 45 se gundos a peça sai dentro da conformidade prevista, esta será a duração prescrita de cada ciclo. 0 operador tem que desenvolver sua tarefa sob este ritmo, senão se acumularão as peças ejetadas pela máquina, comprometendo o fluxo da produção. Enquanto a máquina molda uma nova peça, o operador deve concluir 0 acabamento manual da peça ejetada previamente. Ele deve responder à demanda dentro do tempo estipulado, ainda que ocorram perturbações do processo de produção que exijam sua intervenção. Durante a execução da tarefa, em um dos ciclos, o operador interrompeu 0 acabamento da peça, abriu a porta da máquina e puxou a próxima peça que estava presa ao molde. E comentou após ser indagado sobre o quefazia: É, a gente já sabe, faz uma coisa, mas tem o sentido na outra também. Deu o tempo, a peça não caiu, tá presa. I sto acontece porque a temperatura da máquina sobe. Evidencia-se que o trabalho, apesar de implicar gestos repetitivos, é variável, exigindo atenção e tomada rápida de decisão, conforme discute Assunção 22 .

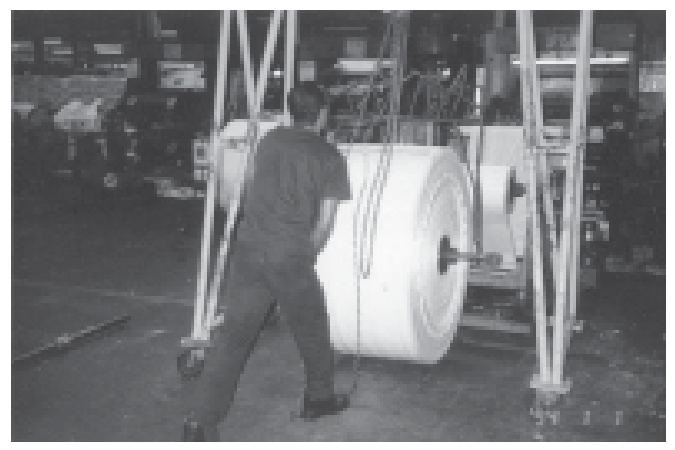

Figura 1. Manuseio de bobinas no setor de extrusão.
As empresas com processo tecnológico à base de injeção, como é o caso das empresas de brinquedos, de caixarias e de tubos e conexões, reconhecidas como aquelas de capital mais intensivo, podem ser situadas entre as organizações de "gestão mais moderna". Suas fábricas apresentam estrutura física diferenciada. No entanto, à organização do espaço físico não corresponde um diferencial na gestão de pessoal. Ao contrário, as exigências temporais são, algumas vezes, mais fortes nessas empresas, cujo maquinário e organização espacial favorecem a manutenção do ritmo da produção sem interrupções. A intensificação do trabal ho devido ao ritmo das máquinas com ciclos muito curtos e ininterruptos foi uma característica dessas empresas. Visava-se à otimização do uso do maquinário mais moderno com a continuidade das tarefas, em detrimento de qualquer controle dos trabalhadores sobre o seu trabalho.

\section{Impressão}

0 deslocamento das bobinas para o setor de impressão, no segmento de sacaria, exige um grande esforço físico. 0 uso de carrinhos não 0 elimina, já que as rodinhas não deslizam com facilidade, devido ao grande peso de algumas bobinas transportadas (Figura 2). Entre as onze empresas de embalagens, apenas duas não realizam o processo de impressão.

\section{Acabamento no segmento de sacaria} O corte e solda e o valvulado

Toda sacaria plástica, com exceção do filme contrátil para embalagem de refrigerantes, bobinas técnicas e bobinas de sacos picotados, é encaminhada ao corte e solda.

Uma vez confeccionado o filme plástico, tendo passado ou não pela impressão, as bobi-

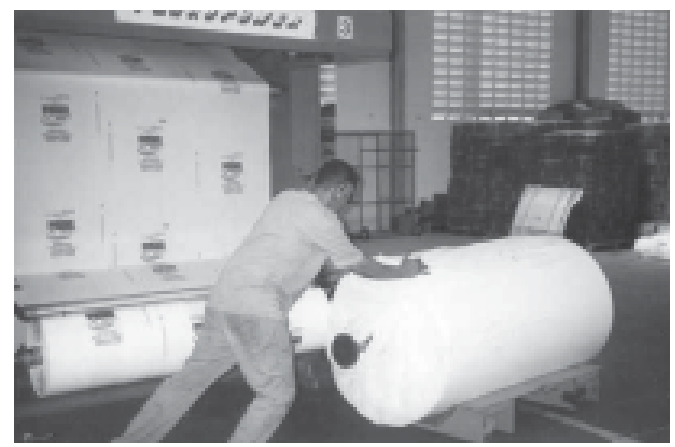

Figura 2. Deslocamento de carga para o setor de impressão. 
nas são encaminhadas para o setor de acabamento, queinicia o processo pelo cortee solda. A bobina plástica é acoplada à máquina de corte $\mathrm{e}$ solda, da qual saem unidades de embalagem, cortadas e fechadas (a depender da sua modalidade) através de um processo à base de calor, a selagem plástica (denominado habitualmentede "solda"). As máquinas de corte e solda têm dimensões e capacidades bem variadas, sendo que o diferencial das máquinas mais modernas é a maior velocidade de produção.

A pós o corte e solda, a embalagem pode ser encaminhada, a depender do fim ao qual se destina, ao acabamento com válvula ou à costura.

As tarefas do acabamento no corte e solda implicam manutenção da postura ortostática durante toda a jornada, ao lado da máquina, desenvolvendo movimentos repetitivos com membros superiores. No setor de valvulado, os ciclos são curtos (em média, 5 segundos) e em cada máquina operam de duas a três operadoras (Figura 3).

0 trabalho nesse setor chama atenção pelo caráter repetitivo, que acompanha o ritmo das máquinas, exigindo a manutenção de posturas penosas, que se constituem em fatores de risco para distúrbios musculoesqueléticos ${ }^{4}$.

Em função das exigências da produção e insuficiência dos meios de trabalho, os trabalhadores desenvolvem competências tácitas a fim de obter os almejados objetivos da produção. No entanto, pode ser que, em decorrência da distância entre o trabalho prescrito e o trabalho real ou no desenvolvimento de habilidades sob pressão temporal para compensar as insuficiências não providas pela organização formal do trabalho e assegurar a qualidade, intensifique-se a exposição a fatores de risco físicos e psicossociais.

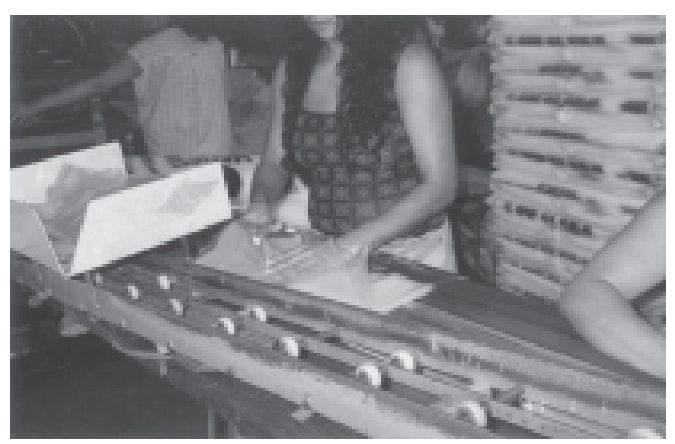

Figura 3. Realização do acabamento de embalagem plástica.

\section{Conclusões}

M udanças na gestão dos negócios, na política de vendas, na captação e manutenção de clientes ea incorporação de novas tecnologias levaram a novas formas de gestão da produção e de gestão de pessoal, com novas tarefas e novas exigências para os trabalhadores no desenvolvimento da atividade laboral.

A modalidade de gestão adotada pelas empresas para melhoria do desempenho no mercado provocou mudanças na organização temporal da produção. A obtenção de uma maior capacidade produtiva, por unidade de tempo, com redução do custo de produção, tem intensificado o ritmo de trabalho, buscando a maior produção por unidade de tempo. Esta reestruturação produtiva determina modificações na gestão da força de trabalho, com novas exigências aos trabalhadores.

Há exigências de desenvolvimento de novas habilidades sensório-motoras pelos trabalhadores para ajustar os efeitos das insuficiências dos meios de produção (máquinas obsoletas, maté ria-prima de baixa qualidade) e do processo mecânico sobre o produto final.

Os mecanismos de controle da produtividade nas empresas permitem afirmar que a distância entre os objetivos globais da produção eas condições concretas de trabal ho explicita-se nas margens estreitas deixadas pela organização do trabaIho para permitir ao trabalhador regular o ciclo de trabalho. Não há planejamento baseado na capacidade de produção ou recursos disponíveis. A demanda do mercado altera o ritmo da produção, determinando mudanças na gestão informal das operações pelas equipes constituídas.

N ovas habilidades se desenvolvem em uma situação de forte constrangimento temporal, que implica a impossibilidade de regular as variabilidades do processo produtivo, sem que isto represente uma hipersolicitação do corpo. A presença de demandas físicas (trabalho repetitivo, levantamento de carga) edemandas psicossociais (baixo controle dos trabalhadores sobre suas tarefas, pressão temporal einsatisfação no trabalho) compõem um universo favorável para a ocorrência de efeitos na saúde dos trabal hadores. 


\section{Colaboradores}

RCP Fernandes realizou o trabalho de campo sob orientação de AA Assunção. As demais etapas do trabalho foram realizadas em conjunto pelos autores.

\section{Referências}

1. Buckle PW, Devereux JJ. The nature of work-related neck and upper limb musculoskeletal disorders. Appl Ergon 2002; 33:207-217.

2. Melhorn JM, Gardner P. How we prevent prevention of musculoskeletal disorders in the workplace. Clin Orthop Relat Res 2004; 419:285-296.

3. M elhorn JM. Cumulative trauma disorders and repetitive strain injuries. The future. Clin Orthop Relat Res 1998; 351:107-126.

4. National Research Council. Institute of M edicine. M usculoskeletal disorders and the workplace: low back and upper extremities. Panel on musculoskeletal disorders and the workplace. Commission on behavioral and social sciences and education. Washington, D.C.: National Academy Press; 2001.

5. Muggleton JM, Allen R, Chappell PH. Hand and arm injuries associated with repetitive manual work in industry: a review of disorders, risk factors and preventive measures. Ergonomics 1999; 42(5):714-739.

6. Reis RJ, Pinheiro TM M, Navarro A, Martin M. Perfil da demanda atendida em ambulatório de doenças profissionais e a presença de lesões por esforços repetitivos. Rev. Saude Publica 2000; 34(3):292-298.

7. Huang GD, Feuerstein M, Sauter SL. Occupational stress and work-related upper extremity disorders: concepts and models. Am J Ind M ed 2002; 41:298314.

8. Bahia. Secretaria da Saúde do Estado. Manual de N ormas e Procedimentos Técnicos para a Vigilância da Saúde do Trabalhador.Salvador: CESAT/SESAB; 2002.

9. M achado JM H. Alternativas e processos de vigilância em saúde do trabalhador: a heterogeneidade da intervenção [tese]. Rio de Janeiro (RJ): Escola Nacional de Saúde Pública; 1996.

10. Pádua Neto A, Souza NV, Barreto RM . Cadeia produtiva petroquímica: ressurge 0 debate. Bahia Análise \& Dados Salvador 2003; 13(3):665-675.

11. Lima FPA. Introdução à análise ergonômica do trabaIho. [ $N$ otas de aula]. Belo Horizonte: s/d; 1995.

12. Bongers PM, Kremer AM, ter Laak J. Are psychosocial factors, risk factors for symptoms and signs of the shoulder, elbow, or hand/wrist?: A review of the epidemiological literature. Am J Ind M ed 2002; 41:315-342.

13. Westgaard RH. Work-related musculoskeletal complaints: some ergonomics challenges upon the start of a new century. Appl Ergon 2000; 31:569-580.

14. Llory M. Acidentes industriais: o custo do silêncio. O peradores privados da palavra e executivos que não podem ser encontrados. Rio de Janeiro: MultiM ais Editorial; 1999.

15. Karasek R, Brisson C, Kawakami N, Bongers P, Houtman I. The Job Content Questionnaire (JCQ): An instrument for internationally comparative assessments of psychosocial job characteristics. J O ccup Health Psychol 1998; 3(4):322-335.

16. Abrahão J. Reestruturação produtiva e variabilidade do trabalho: uma abordagem da ergonomia. Psic: Teor e Pesq 2000; 16(1):49-54.

17. Lewchuk W, De Wolff A, King A, Polanyi M. From job strain to employment strain: health effects of precarious employment. Just Labour 2003; 3:23-35. 
18. Lewchuk W, De Wolff A, King A, Polanyi M. The invisible health risks of precarious employment. AIRAANZ 2005; 117-124.

19. Brito JC. Enfoque de gênero e relação saúde/trabaIho no contexto de reestruturação produtiva e precarização do trabalho. Cad Saude Publica 2000; 16(1):195-204.

20. Olinto G, Oliveira ZLC. Gênero e trabalho precário no Brasil urbano: perspectivas de mudança. In: XIV Encontro Nacional de Estudos Populacionais; 2004; Caxambu.

21. Guérin F, Laville A, Daniellou F, Duraffourg J, Kergue LEN. Compreender o trabalho para transformálo. A prática da ergonomia. São Paulo: Edgard Blucher Ltda.; 2001.

22. Assunção AA. Gesto repetitivo, trabalho variável. In: N eto AC, Salim CA, organizadores. N ovos desafios em saúde e segurança no trabalho. Belo Horizonte: IRT/FUNDACENTRO; 2002.

Artigo apresentado em 17/07/2007

A provado em 22/10/2007 